Article

\title{
Justification of the Energy Use of Cedar Husk Waste as an Environmentally Friendly Additive for Co-Combustion with Coal
}

\author{
Yankovsky Stanislav 1,2,*(D), Tolokol'nikov Anton ${ }^{1}$, Berezikov Nikolay ${ }^{1,2}$ and Gubin Vladimir ${ }^{1}$ \\ 1 The Butakov Research Center, National Research Tomsk Polytechnic University, 30 Lenin Ave., Main Building, \\ Office 127, 634050 Tomsk, Russia; anton.tolokolnikov1@gmail.com (T.A.); nib3@tpu.ru (B.N.); \\ gubin@tpu.ru (G.V.) \\ 2 Research Laboratory of Catalysis and Conversion of Carbon-Containing Materials to Produce Useful \\ Products, Institute of Energy, T.F. Gorbachev Kuzbass State Technical University, St. Spring, 28, \\ 650000 Kemerovo, Russia \\ * Correspondence: jankovsky@tpu.ru
}

Citation: Stanislav, Y.; Anton, T.; Nikolay, B.; Vladimir, G. Justification of the Energy Use of Cedar Husk Waste as an Environmentally Friendly Additive for Co-Combustion with Coal. Energies 2021, 14, 7027. https://doi.org/10.3390/en14217027

Academic Editor:

Andrzej Teodorczyk

Received: 8 October 2021

Accepted: 24 October 2021

Published: 27 October 2021

Publisher's Note: MDPI stays neutral with regard to jurisdictional claims in published maps and institutional affiliations.

Copyright: (c) 2021 by the authors. Licensee MDPI, Basel, Switzerland. This article is an open access article distributed under the terms and conditions of the Creative Commons Attribution (CC BY) license (https:/ / creativecommons.org/licenses/by/ $4.0 /)$.

\begin{abstract}
In this paper, the properties of ignition of mixed fuel pellets formed on the basis of fairly typical energy coal and wood industry waste in the form of cedar husks are experimentally established. The technical characteristics of the initial fuel components and the mixtures based on them, the ignition delay times for different mass concentrations of biomass in coal, and the composition of flue gases formed during the thermal decomposition of these mixed fuels and their base components were determined. Pellets of mixed fuels were made by a hydraulic press. The experiments were performed in an air environment at temperatures from $600{ }^{\circ} \mathrm{C}$ to $800{ }^{\circ} \mathrm{C}$. Recording of the processes of pellet ignition and combustion was carried out using a high-speed video camera with an image format of $1024 \times 1024$ pixels, and a frame rate up to 500 frames per second. The analysis of the flue gas composition was performed using a Test- 1 factory gas analyzer (BONER Co.). It was found that the increase in the share of biomass up to $50 \%$ in the mixed fuel led to a significant reduction in the ignition delay time to less than $1 \mathrm{~s}$ and the sequestration of sulfur oxide emissions by $37.6 \%$ and of nitrogen oxides by $3.8 \%$ in the studied granular mixed fuels.
\end{abstract}

Keywords: coal; biomass; recycling; mixed fuel; pellets; thermal decomposition; combustion; reduction of harmful emissions

\section{Introduction}

According to the well-known statistical company ExxonMobil's corporate headquarters, the share of coal consumption reduction for electricity generation by 2040 will be less than $11 \%$ compared to that of 2017. At the same time, the share of other energy resources will grow slightly [1]. Based on the above, the relevance of solving problems to reduce emissions from coal-fired power plants will remain at a high level for at least the next two decades. In recent years, various environmentally friendly methods for solid fuels combustion have been developed. One of these methods is the combustion of multicomponent mixed fuels based on different grades of coal mixed with biomass (waste from wood processing, agriculture, the food industry, etc.) both in their solid state and in the form of various suspensions [2-7]. Such alternative and eco-friendly fuels can be solid pelletized fuels based on coal and biomass, which will, in turn, reduce the amount of accumulated waste from the agricultural and forestry industries. Attempts to use plant biomass for energy have been made several times [8-10]. However, the introduction of mixed fuels based on coal and biomass at large thermal power plants raises many questions about how to deliver, store, prepare and then co-burn them with coal. Numerous attempts to co-burn biomass with coal [11-15] have been made by highly developed countries such as the United States, India, Denmark, and China, but these projects have been implemented 
on an industrial scale only at several TPPs, since multiple issues relating to fuel storage and preparation systems, systems for feeding such mixed fuels, and their co-combustion have not yet been resolved $[16,17]$. This problem could be solved for small-scale power generation with the use of mixed pellets based on different grades of coal and biomass (cedar husk) $[18,19]$ formed using standard granulators without the application of additional binding components $[20,21]$.

The main problem with the use of granular mixed fuels in small- or large-scale power engineering, the solution for which is necessary when developing technologies for burning such fuels, is that, as established by the results of research [22], the ignition delay times of droplets and particles of any liquid [23,24], solid [25,26], or slurry [27,28] fuels significantly depend on the size of the particles (or droplets) [29]. The larger the size of these particles, the longer the ignition delay time, respectively [30]. In this case, problems arise when implementing the processes of manufacturing mixed pellets and burning them. The larger the mixed fuel pellets, the simpler the technology and the lower the cost of their production, but when burning large pellets, serious difficulties arise, and the ignition delay times increase when they directly enter the boiler's furnace space. In this regard, one of the main, and perhaps the most, important task in the development of technologies for the manufacture and combustion of pellets from cedar-coal mixtures is to establish a relationship between the conditions and characteristics of ignition and the particle size under certain conditions, such as permissible temperatures of the oxidizing medium (air).

To date, the analysis results of the ignition patterns of mixed fuel pellets based on coal and cedar husks have not been published.

The purpose of this paper is to substantiate an eco-efficient and cost-effective technology for recycling waste from the food and forest industry as a result of burning fuel mixtures based on coal and cedar husks by experimental studies of the conditions and characteristics of pellet ignition of such fuel mixtures in an oxidizing environment under intense radiation heating, corresponding to the operating conditions of hot water boilers of small power engineering.

\section{Methods of Experimental Research}

The initial components used were $\mathrm{T}$ grade coal (Alardinskoe deposit) and cedar husk (from the Tomsk region, the area where cedar pine grows). The initial components were crushed in a ball drum mill and then sieved through a sieve system. The typical size of the coal particles and cedar husk was 80 and 200 microns, respectively. The crushed components were mixed as a fuel mixture in a ball drum mill (bituminous coal/cedar husk) with the following mass ratios: $90 \% / 10 \%, 75 \% / 25 \%$, and $50 \% / 50 \%$.

The technical characteristics (calorific value, moisture content, ash content, volatile yield) of the base fuel components, as well as the mixtures based on them, were determined at the preliminary stage of research of the mixed fuel pellets. The results of the technical analysis are presented in Table 1, where:

- $\mathrm{W}^{\mathrm{a}}$ is the moisture content of the studied fuels;

- $\quad \mathrm{A}^{\mathrm{d}}$ is the ash content of the studied fuels;

- $\quad \mathrm{V}^{\text {daf }}$ is the yield of volatile substances of the studied fuels;

- $\mathrm{Q}$ is the calorific value of the studied fuels.

Table 1. Properties and elemental composition of fuel components.

\begin{tabular}{|c|c|c|c|c|c|c|c|c|c|}
\hline \multirow{2}{*}{$\begin{array}{c}\text { Fuel(Coal / } \\
\text { Cedar Husk), \% }\end{array}$} & \multirow{2}{*}{$\begin{array}{c}\text { Calorific Value, } \\
\text { Q, MJ/kg }\end{array}$} & \multicolumn{3}{|c|}{ Technical Analysis, $\%$} & \multicolumn{5}{|c|}{ Elemental Composition of Dry Matter, \% } \\
\hline & & $\mathbf{W}^{\mathbf{a}}$ & $A^{d}$ & $V^{\text {daf }}$ & $C^{d}$ & $H^{d}$ & $\mathbf{N}^{\mathrm{d}}$ & $S^{d}$ & $\mathrm{O}^{\mathrm{d}}$ \\
\hline 100_CT $/ 0$ & 24.18 & 4.64 & 20.86 & 27.38 & 84.3 & 6.4 & 2.9 & 0.600 & 5.8 \\
\hline 0_CT/100 & 20.39 & 7.63 & 1.59 & 80.15 & 51.4 & 6.7 & 1.2 & - & 40.7 \\
\hline 90_CT $/ 10$ & 21.39 & 5.50 & 19.33 & 47.39 & - & - & - & - & - \\
\hline 75_CT $/ 25$ & 21.19 & 5.95 & 16.21 & 78.82 & - & - & - & - & - \\
\hline 50_CT $/ 50$ & 20.56 & 6.51 & 11.83 & 65.17 & - & - & - & - & - \\
\hline
\end{tabular}


Analysis of the results shown in Table 1 allows us to determine the effect of cedar husk on the technical characteristics of such fuel mixtures. The increase in the proportion of cedar husks to $50 \%$ in the mixed fuel led to a decrease in calorific value by $14.9 \%$, and in ash content by 1.76 times relative to the homogeneous coal. The moisture content and volatiles yield of the equilibrium mixture of coal and cedar husk relative to the homogeneous $\mathrm{T}$ grade coal increased by 1.4 and 2.4 times, respectively.

The preparation of the pellets of the studied mixed fuels was carried out by cold pressing using a hydraulic manual press. The cold pressing method eliminates energy costs for pre-drying fuel mixture samples, heating them, or additional sintering at relatively low temperatures. Mixed fuel samples were placed in a matrix with a through hole $8 \mathrm{~mm}$ in diameter and a thrust cup fixed at the base [24]. Pressing was performed by a punch of the corresponding diameter fixed on the hydraulic mechanism of the press with a force of 2 metric tons. A pressing matrix of a given configuration was used to form fuel pellets of a constant shape. The sample weight did not exceed $0.9 \mathrm{~g}$ (the range of mass changes was no more than $\pm 0.01 \mathrm{~g}$ ) [24]. A schematic diagram of the installation for the formation of cedar-coal granular fuels and the obtained samples are shown in Figure 1.

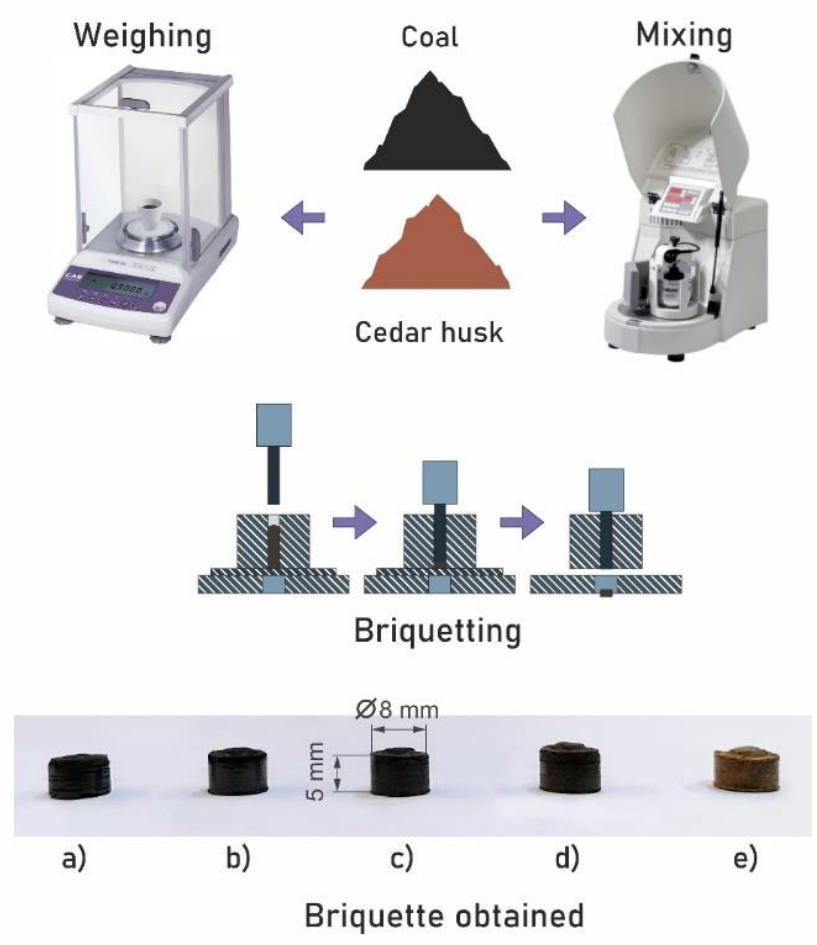

Figure 1. Schematic diagram of the preparation of mixed fuel pellets: (a) pellets of homogeneous coal, (b) pellets with a cedar husk content of $10 \%$, (c) pellets with a cedar husk content of $25 \%$, (d) pellets with a cedar husk content of $50 \%$, and (e) pellets of homogeneous cedar husk.

The granules size shown in Figure 1 was $8 \mathrm{~mm}$ in diameter and $5 \mathrm{~mm}$ in height. Deviations of the granule size from the average values did not exceed $\pm 0.5 \mathrm{~mm}$.

An experimental stand was developed for determining the ignition delay times of the investigated pellets of mixed fuels and their initial components. The schematic diagram of the experimental setup is shown in Figure 2. The main elements of the stand are a TP-1400 temperature-controlled oven with a digital temperature controller (accuracy of measurement $\pm 1{ }^{\circ} \mathrm{C}$ ); a high-speed video camera with an image format of $1024 \times 1024$ pixels and a frame frequency up to $10^{5}$ per second; a platform of the coordinate mechanism intended for pellets input into the furnace with an accuracy of movement less than $1 \mathrm{~mm}$; a TEST 1 gas analyzer, designed to analyze the composition of flue gases formed after the thermal decomposition of the fuel pellets; and an OVEN TRM10 PID temperature controller with 
a thermocouple, designed to monitor the temperature of still air inside the combustion chamber [24].

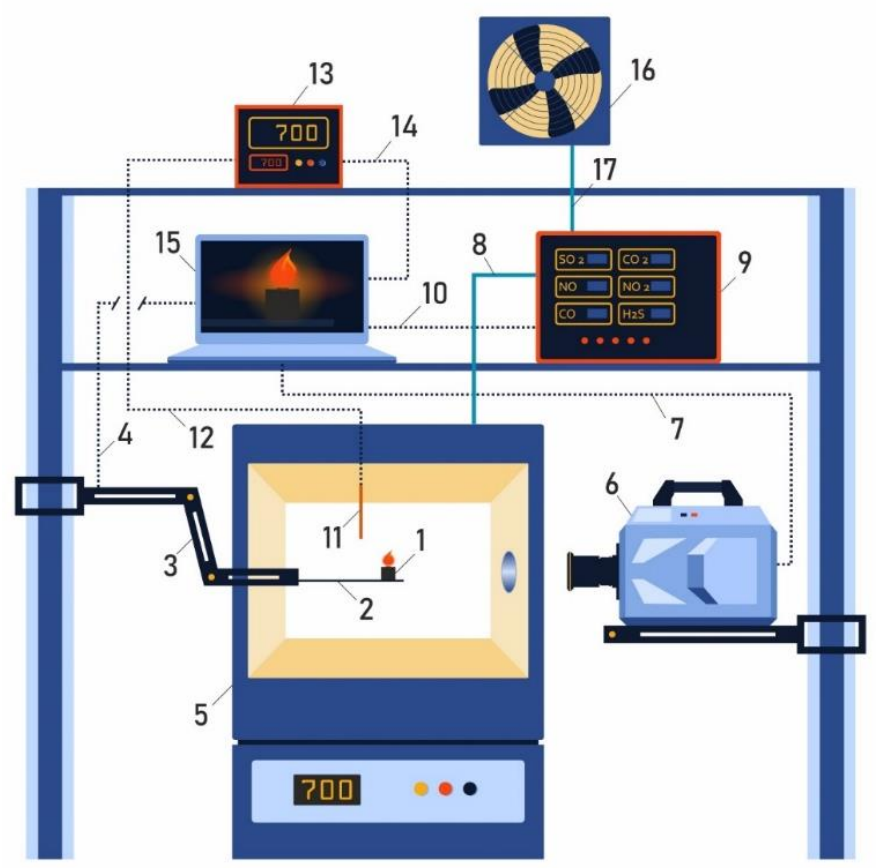

Figure 2. Schematic diagram of experimental setup for determining the ignition delay times and gas analysis of mixed fuel pellets based on T grade coal and cedar nut husks. 1-Pellets of mixed fuel; 2-platform of coordinate mechanism; 3-coordinate mechanism; 4-connection of coordinate mechanism and laptop; 5-camera with adjustable temperature; 6-high-speed video camera; 7-channel for data transfer of video recording of the fuel combustion process; 8 -supply line to flue gas analyzer; 9-gas analyzer; 10 - connection of gas analyzer and laptop; 11-thermocouple; 12 - connection of thermocouple and converter; 13 - thermocouple signal converter; 14 -connection of thermocouple signal converter and laptop; 15-laptop; 16-flue gas release to atmosphere; 17—ventilation system.

The method of studying the conditions and processes of ignition delay of mixed fuel pellets (formed from coal and cedar husks) and analyzing the composition of gases formed during fuel combustion included several stages. The fuel pellet (1) was placed on the holder (2) of the coordinate mechanism (3); the coordinate mechanism was driven by a signal sent from a laptop via a connection channel (4). The fuel pellet (1) was placed in a preheated temperature-controlled oven (5) (the heating range was from $600{ }^{\circ} \mathrm{C}$ to $800{ }^{\circ} \mathrm{C}$ ). Simultaneously with the movement of the coordinate mechanism into the combustion chamber, video recording was performed until the ignition and combustion of the fuel pellet (6-7) occurred. The ignition delay time was considered to be the time from the moment the fuel pellet enters the camera focus to the appearance of a glow on the surface of the pellet corresponding to the beginning of the thermal decomposition process. Flue gases formed during the thermal decomposition of fuel pellets were sent to a pre-calibrated gas analyzer (9) via the main gas path (8), and signals from the gas analyzer sensors were recorded on a laptop via the connection channel (10). The temperature in the combustion chamber was controlled using a platinum-rhodium thermocouple (11) and recorded via the connection channel (12) via a PID temperature controller (13) connected via the connection channel (14) to the laptop (15). The analyzed flue gases were removed through the ventilation channel (16) to the environment using forced ventilation (17). The errors in determining $t_{\text {ig }}$ were systematic, less than 3\%, and random, less than 3.5\%. Experiments on the analysis of the component composition of flue gases for each mixture and initial components were carried out at least five times at a temperature of $600^{\circ} \mathrm{C}$; the relative error was less than $8 \%$. 


\section{Results and Discussion}

Experimental studies were carried out at a temperature (external to the fuel pellet) of the medium from $600{ }^{\circ} \mathrm{C}$ to $800{ }^{\circ} \mathrm{C}$. Figure 3 shows typical images of pellets at the time of fuel injection into the combustion chamber and video frames of the processes at the initial moment of ignition and intense combustion. It was established that pellets made of $\mathrm{T}$ grade coal and fuel mixtures with cedar husks in some cases (at low biomass fractions and low temperatures) ignited when they were in the combustion chamber for a sufficiently long time. An increase in the proportion of cedar husks in the fuel mixture of more than $30 \%$ led to an intensification of the ignition processes of such fuels (ignition delay times of less than $1 \mathrm{~s})$.

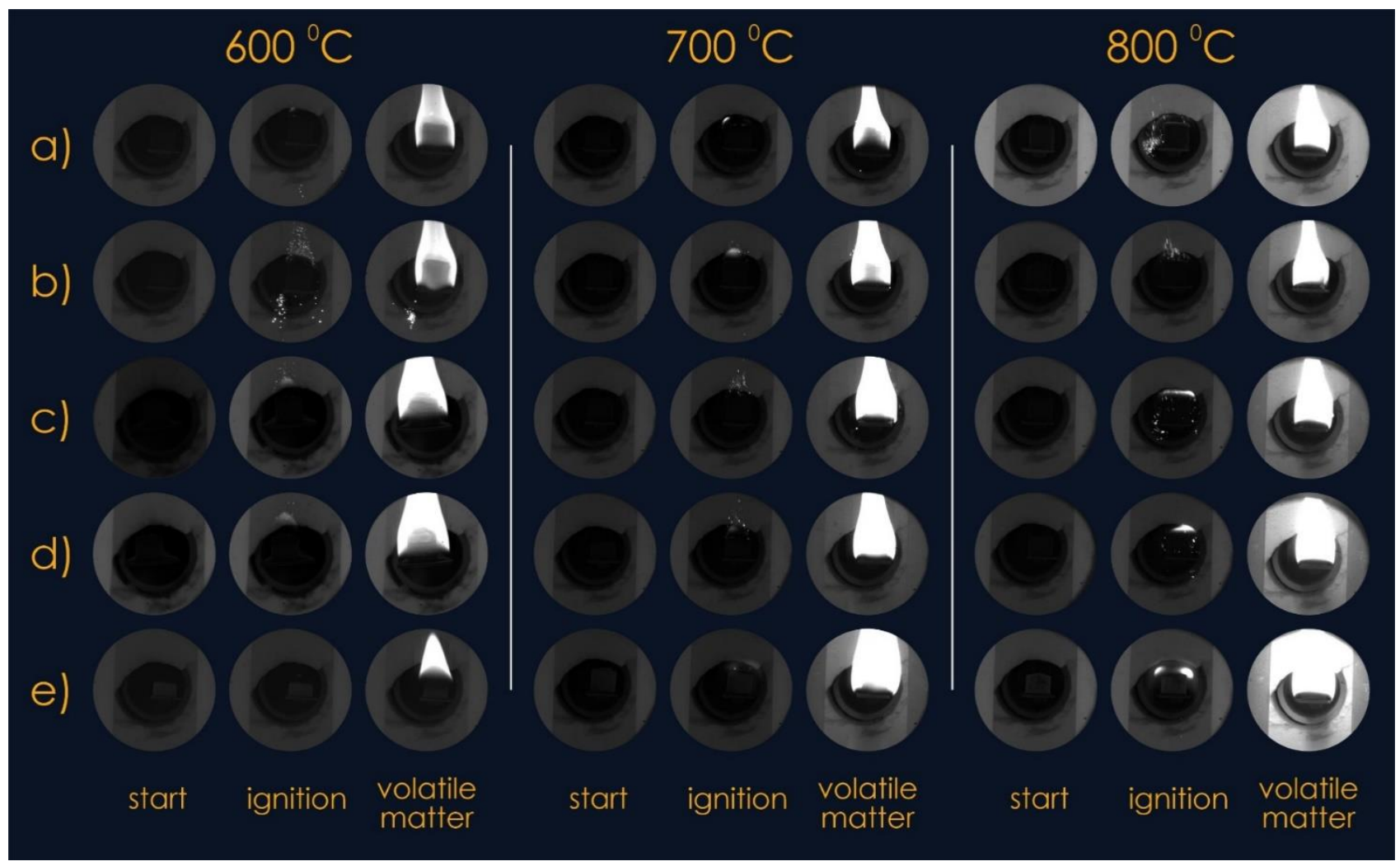

Figure 3. Video frames of the thermal decomposition process of mixed fuel pellets in the temperature range from $600{ }^{\circ} \mathrm{C}$ to $800{ }^{\circ} \mathrm{C}$ : (a) $100 \%$ coal; (b) $90 \%$ coal, $10 \%$ cedar husk; (c) $75 \%$ coal, $25 \%$ cedar husk; (d) 50\% coal, $50 \%$ cedar husk; and (e) $100 \%$ cedar husk.

Figures 3 and 4 show the results of experiments on ignition delay times for the pellets of mixed fuels when the wood biomass concentration changed from $10 \%$ to $50 \%$ over a wide temperature range in the combustion chamber $\left(600^{\circ} \mathrm{C}, 700^{\circ} \mathrm{C}, 800^{\circ} \mathrm{C}\right)$. 


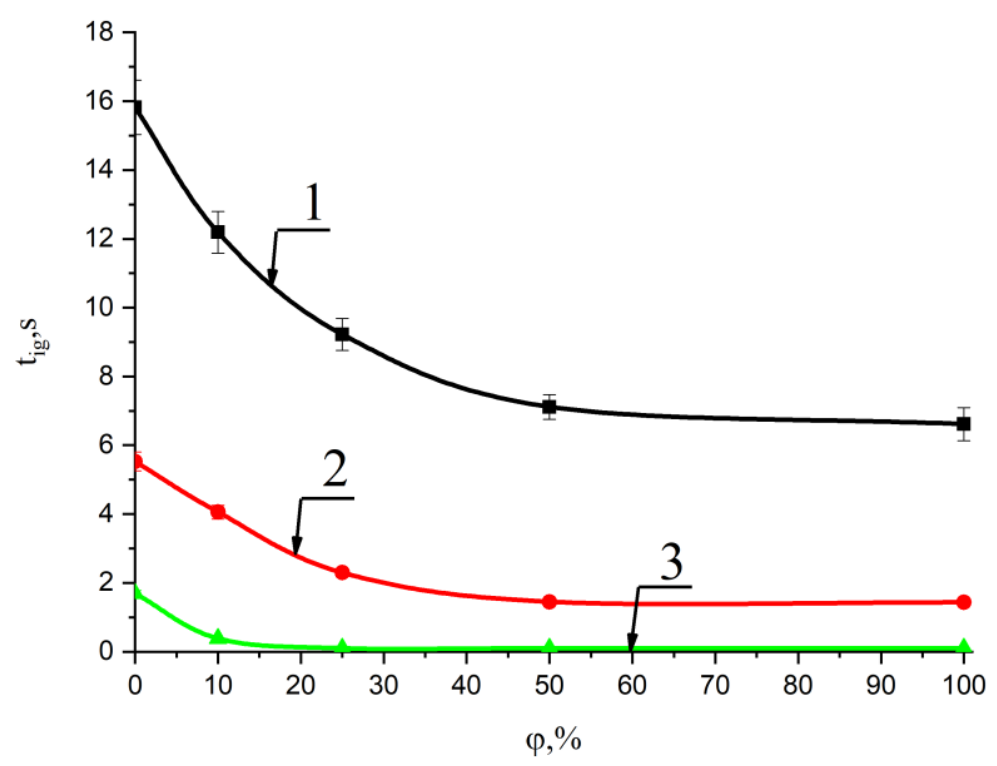

Figure 4. Change in the ignition delay time of mixed fuel pellets based on $\mathrm{T}$ grade coal with an increase in the concentration of cedar husks at ambient temperatures: $1-600{ }^{\circ} \mathrm{C} ; 2-700{ }^{\circ} \mathrm{C}$; and $3-800{ }^{\circ} \mathrm{C}$. The $\varphi$ coefficient shows the concentration of the cedar husk component in a mixture with coal.

Analysis of the research results presented in Figure 4 made it possible to establish that the ignition delay time of the fuel mixture based on T coal and $50 \%$ cedar husk at $800{ }^{\circ} \mathrm{C}$ in the combustion chamber was less than $0.5 \mathrm{~s}$. It can be concluded that ignition occurred at sufficiently small values of the ignition time delay (less than $2 \mathrm{~s}$ ) even for sufficiently large characteristic granule sizes (diameter of $8 \mathrm{~mm}$, height of $5 \mathrm{~mm}$ ) with an increase in the biomass fraction up to $30 \%$. It was also less than $0.5 \mathrm{~s}$ with an increase in the share of cedar husk up to $50 \%$.

This result is due to the fact that the ignition of the pellets mainly occurred on a small area of its surface, which was no more than $20 \%$ of its total area. Most likely, the ignition took place in a place corresponding to the maximum initial concentration of the gaseous products of the thermal decomposition of the latter. Volatiles formed as a result of the pyrolysis of wood and coal rose up during high-temperature heating, and their concentration in the region above the pellets (Figure 3) became maximum where the pellets ignited.

The combustion of mixed fuel pellets based on T coal and cedar husk waste was accompanied by a significant yield of gaseous products (Figure 3).

Figure 5 shows the results of the experimental determination of the $t_{i g}$ ignition delay times of the main components-T grade coal and wood (cedar husk) - as well as pellets of the mixed fuels based on them. A lower temperature limit $\left(T=600^{\circ} \mathrm{C}\right)$ was set, which corresponds to the limit conditions for the stable ignition of such fuels. At lower temperatures, the fuel pellets often did not ignite for $30 \mathrm{~s}$. Therefore, the results of the experimental studies at temperatures below the limit of stable ignition $\left(600^{\circ} \mathrm{C}\right)$ were not considered.

Analysis of Figure 5 allowed us to determine the effect of temperature on the ignition delay times of mixed fuel pellets based on $\mathrm{T}$ grade coal and cedar husks.

It was found that the decrease in the ignition delay time of the studied fuel pellets at a temperature of $700{ }^{\circ} \mathrm{C}$ with an increase in the proportion of cedar husks to $50 \%$ was $73.8 \%$, and at a temperature of $800{ }^{\circ} \mathrm{C}$ was more than $95 \%$. The obtained results allow us to prove that the addition of cedar husk components to coal leads to an intensification of the processes of thermal decomposition beginning in a wide temperature range from $600{ }^{\circ} \mathrm{C}$ to $800{ }^{\circ} \mathrm{C}$. It can be concluded that less energy is needed for hot water and steam boiler heating, but higher temperatures in the furnace space during its operation result in faster ignition processes of granular mixed fuels compared to pellets made of homogeneous coal. 


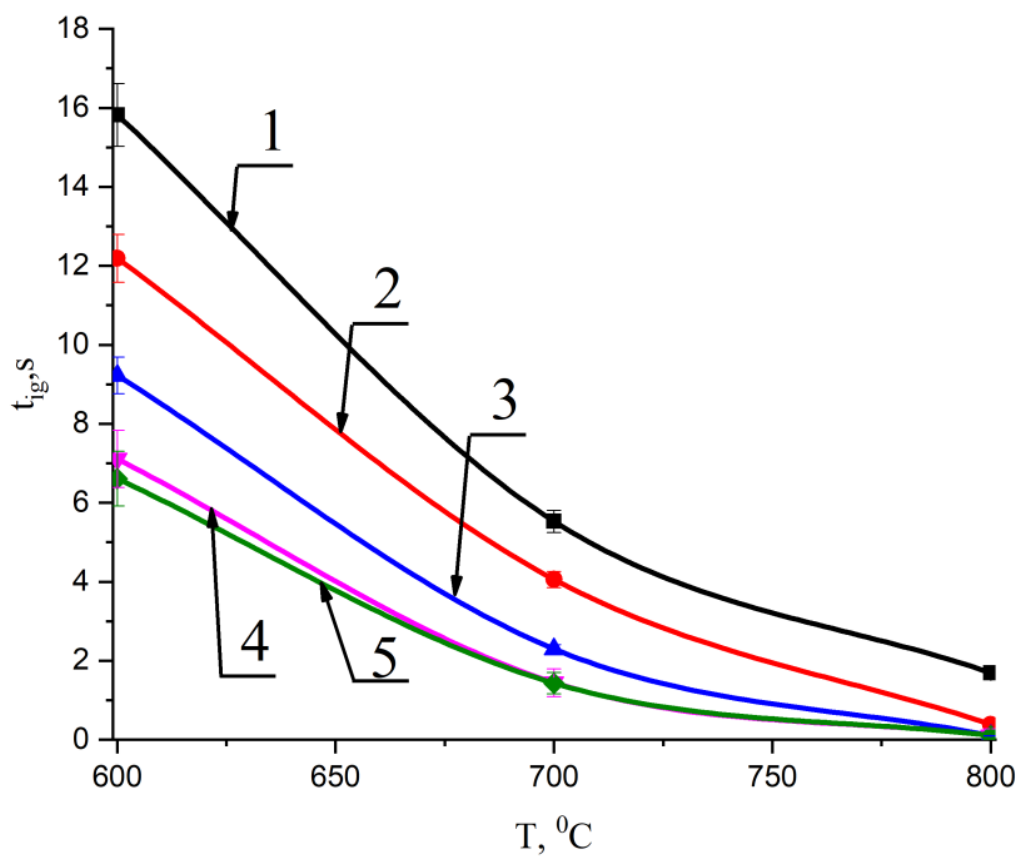

Figure 5. Change in ignition delay times for pellets made of $\mathrm{T}$ grade coal, cedar husks, and mixtures based on them with temperature at different concentrations of the second component: 1-100\% coal; $2-90 \%$ coal, $10 \%$ cedar husk; $3-75 \%$ coal, $25 \%$ cedar husk; $4-50 \%$ coal, $50 \%$ cedar husk; and $5-100 \%$ cedar husk.

Continuous gas analysis of their thermal decomposition process was performed in order to justify the reduction of the negative impact of the studied mixed pellets and pellets made of the initial components on the environment. The studies were carried out at a temperature of thermal decomposition of fuels equal to $600{ }^{\circ} \mathrm{C}$.

Figures 6 and 7 show the results of experimental studies to reduce the negative impact on the environment of anthropogenic gases (sulfur oxides, nitrogen oxides) in the composition of volatile flue gas compounds formed during the thermal decomposition of mixed fuel pellets based on T grade coal and cedar husks.

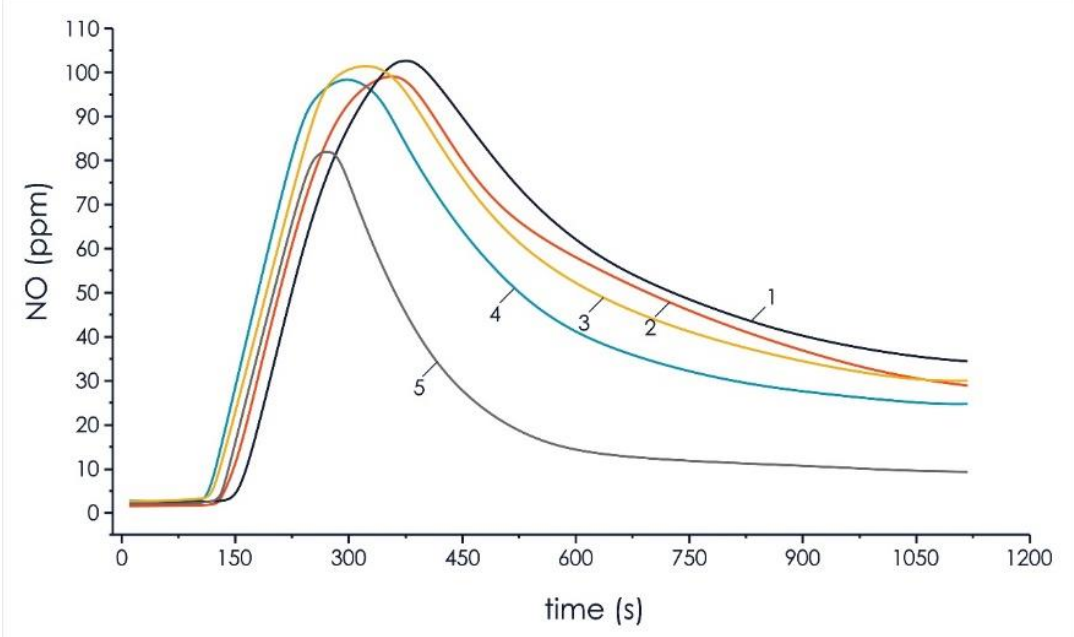

Figure 6. Analysis of nitrogen oxides concentration in the composition of volatile flue gas compounds of the investigated pellets of the initial components and mixtures based on them: $1-100 \%$ coal; $2-90 \%$ coal, $10 \%$ cedar husk; $3-75 \%$ coal, $25 \%$ cedar husk; $4-50 \%$ coal, $50 \%$ cedar husk; and 5-100\% cedar husk. 


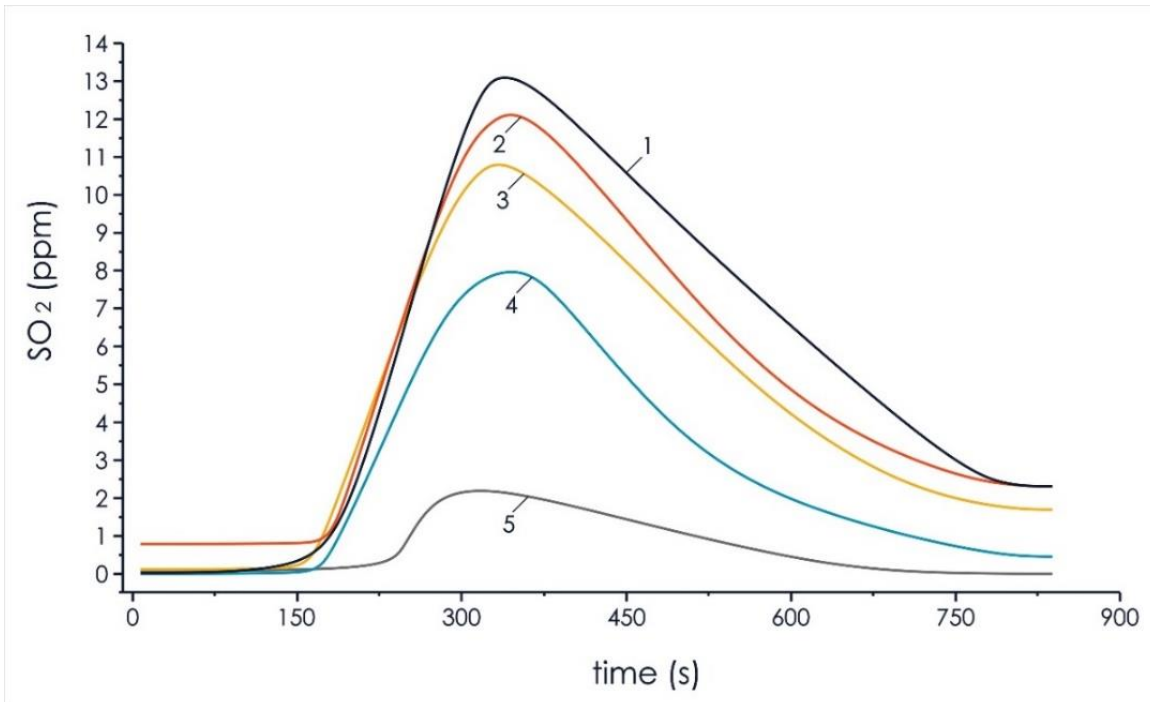

Figure 7. Analysis of sulfur oxides concentration in the composition of volatile flue gas compounds of the investigated pellets of the initial components and mixtures based on them: $1-100 \%$ coal; $2-90 \%$ coal, $10 \%$ cedar husk; $3-75 \%$ coal, $25 \%$ cedar husk; $4-50 \%$ coal, $50 \%$ cedar husk; and $5-100 \%$ cedar husk.

Analysis of the results of the experiments on the formation of nitrogen oxide (Figure 6) with an increase in the share of wood biomass to $50 \%$ showed a decrease in gas concentration of 3.8\%. This effect can be justified by the fact that all processes of the thermal decomposition of mixed fuels based on coal and biomass occur at lower temperatures, which reduced the formation of this oxide to $4 \%$ in the studied mixed pellets.

The results of the experimental study of the formation of sulfur dioxide during the thermal decomposition of the pellets of mixed fuels are shown in Figure 7.

It can be seen in Figure 7 that the increase of biomass concentration in the mixed fuel led to a significant decrease in sulfur dioxide, $37.5 \%\left(\mathrm{SO}_{2}\right.$ content of $\left.8.4 \%\right)$, in relation to the formation of the same gas in a pellet of homogeneous $\mathrm{T}$ grade coal $\left(\mathrm{SO}_{2}\right.$ content of $13.3 \%$ ). The obtained results show that it is possible to significantly (up to $40 \%$ ) reduce the negative impact of such gases from energy sources on the environment when using mixed fuels based on coal and cedar husks.

Based on the results of the experimental studies performed on the example of a mixture of T grade coal and wood, we can conclude that the hypothesis put forward earlier [24] regarding the mechanism of sulfur oxides sequestering during the joint thermal decomposition of crushed coal and wood (not only pine, but also in the form of waste from processing cedar husks) is justified. Intense evaporation of the atmospheric moisture absorbed by the cedar husk occurred when it was heated. An additional output of hygroscopic bound moisture occurred when temperatures corresponding to the interval of thermal decomposition of biomass were reached. The process of thermal decomposition of the organic part of lignite occurred with the formation of volatile particles, carbon-based coke, and the release of the mineral part (calcium and aluminum oxides) during the same time period. Sulfur oxides were formed in the furnace space as the temperature of the volatiles increased, which interacted chemically with water vapors heated to high temperatures. As a result, sulfuric acid vapors were formed, which interact with metal oxides to form salts of these metals-calcium and aluminum sulfates. Calcium is the main element that initiates the formation of sulfate since its concentration in the solid products of the thermal decomposition of most coals is high. It also makes up the main part of wood ash. It can be concluded based on the above that wood biomass based on cedar nut processing waste is also a component for mixed fuels based on coal and biomass which contributes to the sequestration of sulfur oxides in the products of their thermal decomposition. 
The results shown in Figures 6 and 7 reflect a decrease in the concentration of harmful emissions of nitrogen oxides and sulfur oxides with an increase in the proportion of cedar husks in the composition of the mixed fuel pellets. The decrease in the peak concentration of nitrogen oxides and sulfur oxides in the composition of volatile flue gas compounded during the thermal decomposition of the mixture of lean coal and cedar husk in the ratio of $50 \% / 50 \%$ relative to homogeneous lean coal was $3.8 \%$ and $37.6 \%$, respectively.

Analysis of the results of the experimental studies also validates the feasibility of a theoretical analysis of chemical reactions between gaseous and solid products from the thermal decomposition of particles of crushed bituminous coal and fine cedar husk. An experimental study of such processes is rather difficult due to their multi-factor nature and the distribution of mixed fuel pellets in all three coordinate directions in the real conditions of boiler furnaces. Modern developments of computer technology allow for the mathematical modeling of heat and mass transfer in a system of several coal and wood particles, taking into account the processes of concentration changes of gaseous and solid substances and compounds as a result of their chemical interaction with each other at rates that depend on the temperature and concentrations of reacting components within the pellets.

For further studies, a sequestration mechanism methodology is proposed, which consists of the chemical reactions listed below [31,32].

A decrease in the yield of sulfur oxides occurs due to their interaction with water vapor (as a result, sulfuric acid is formed) and the subsequent reactions of metals and their oxides contained in the mixed fuel at high temperatures with sulfuric acid:

$$
\begin{aligned}
& \mathrm{Fe}_{2} \mathrm{O}_{3}+3 \mathrm{H}_{2} \mathrm{SO}_{4} \rightarrow \mathrm{Fe}_{2}\left(\mathrm{SO}_{4}\right)_{3}+3 \mathrm{H}_{2} \mathrm{O} \\
& \mathrm{Al}_{2} \mathrm{O}_{3}+3 \mathrm{H}_{2} \mathrm{SO}_{4} \rightarrow \mathrm{Al}_{2}\left(\mathrm{SO}_{4}\right)_{3}+3 \mathrm{H}_{2} \mathrm{O} \\
& \mathrm{Mg}+\mathrm{H}_{2} \mathrm{SO}_{4} \rightarrow \mathrm{MgSO}_{4}+\mathrm{H}_{2} \\
& \mathrm{CaO}+\mathrm{H}_{2} \mathrm{SO}_{4} \rightarrow \mathrm{CaSO}_{4}+\mathrm{H}_{2} \mathrm{O} \\
& \mathrm{Al}_{2} \mathrm{O}_{3}+3 \mathrm{H}_{2} \mathrm{SO}_{4} \rightarrow \mathrm{Al}_{2}\left(\mathrm{SO}_{4}\right)_{3}+3 \mathrm{H}_{2} \mathrm{O} \\
& \mathrm{NO}_{2}+2 \mathrm{H}_{2} \rightarrow \mathrm{N}_{2}+2 \mathrm{H}_{2} \mathrm{O}
\end{aligned}
$$

The regularities established in previous experiments illustrate the synergistic effect of the combustion of mixed fuels and the need for a detailed study at the stage of their formation not only of coals, which are the basis of such fuels, but directly of the mixed fuel itself. In this case, the maximum positive effect of using fuels based on coal and cedar husk can be achieved.

\section{Conclusions}

The results of the experimental studies allow us to justify the possibility of energy use of mixed fuel pellets based on coal and cedar nut processing waste. Pellets formed by cold pressing had stable ignition at temperatures above $600^{\circ} \mathrm{C}$, which corresponds to the actual operating conditions of low-power boilers and heating installations of private households. Pellets with a crushed cedar husk content of more than $10 \%$ ignited almost instantly (no more than $0.1 \mathrm{~s}$ ) when the temperature rose to $800^{\circ} \mathrm{C}$.

The composition of the flue gases formed during the thermal decomposition of the mixed fuels was analyzed. It was found that an increase in the share of biomass in the mixed fuel to $50 \%$ led to a decrease in the concentration of sulfur oxides at the peak level by more than a third. The decrease in nitrogen oxides with the increase in the proportion of biomass in the mixture was insignificant.

Author Contributions: Conceptualization, Y.S.; validation, formal analysis, investigation, writing—original draft preparation, Y.S., T.A.; visualization, B.N.; project administration, G.V. All authors have read and agreed to the published version of the manuscript.

Funding: The work was carried out with financial support in accordance with additional agreement No. 075-03-2021-138/3 for the provision of subsidies from the federal budget to finance the implementation of the state assignment for the provision of public services (internal number 075-GZ/X4141/687/3). 
Data Availability Statement: The data presented in this study are available on request from the corresponding authors.

Conflicts of Interest: The authors declare no conflict of interest.

\section{References}

1. Oil I ExxonMobil. Available online: https:// corporate.exxonmobil.com/Operations/Oil (accessed on 11 May 2021).

2. Sher, F.; Pans, M.A.; Sun, C.; Snape, C.; Liu, H. Oxy-fuel combustion study of biomass fuels in a $20 \mathrm{kWth}$ fluidized bed combustor. Fuel 2018, 215, 778-786. [CrossRef]

3. Verma, V.K.; Bram, S.; Delattin, F.; Laha, P.; Vandendael, I.; Hubin, A.; De Ruyck, J. Agro-pellets for domestic heating boilers: Standard laboratory and real life performance. Appl. Energy 2012, 90, 17-23. [CrossRef]

4. Coimbra, R.N.; Paniagua, S.; Escapa, C.; Calvo, L.F.; Otero, M. Thermal Valorization of Pulp Mill Sludge by Co-processing with Coal. Waste Biomass Valorization 2016, 7, 995-1006. [CrossRef]

5. Wannapeera, J.; Fungtammasan, B.; Worasuwannarak, N. Effects of temperature and holding time during torrefaction on the pyrolysis behaviors of woody biomass. J. Anal. Appl. Pyrolysis 2011, 92, 99-105. [CrossRef]

6. GROWING POWER. Advanced Solutions for Bioenergy Technology from Finland-PDF Free Download. Available online: http:/ / docplayer.net/39085396-Growing-power-advanced-solutions-for-bioenergy-technology-from-finland.html (accessed on 17 March 2021).

7. Baliban, R.C.; Elia, J.A.; Floudas, C.A. Toward Novel Hybrid Biomass, Coal, and Natural Gas Processes for Satisfying Current Transportation Fuel Demands, 1: Process Alternatives, Gasification Modeling, Process Simulation, and Economic Analysis. Ind. Eng. Chem. Res. 2010, 49, 7343-7370. [CrossRef]

8. Sonobe, T.; Worasuwannarak, N.; Pipatmanomai, S. Synergies in co-pyrolysis of Thai lignite and corncob. Fuel Process. Technol. 2008, 89, 1371-1378. [CrossRef]

9. Kuznetsov, G.V.; Yankovskii, S.A. Conditions and Characteristics in Ignition of Composite Fuels Based on Coal with the Addition of Wood. Therm. Eng. 2019, 66, 133-137. [CrossRef]

10. Muthuraman, M.; Namioka, T.; Yoshikawa, K. A comparative study on co-combustion performance of municipal solid waste and Indonesian coal with high ash Indian coal: A thermogravimetric analysis. Fuel Process. Technol. 2010, 91, 550-558. [CrossRef]

11. Arvelakis, S.; Frandsen, F.J. Melting behavior of ashes from the co-combustion of coal and straw. Energy Fuels 2007, 21, 3004-3009. [CrossRef]

12. Burdukov, A.P.; Butakov, E.B.; Chernova, G.V. Ignition and Lighting of Coal-Fired Boilers with Mechanically Activated Micronized Coal instead of Fuel Oil. J. Eng. Thermophys. 2020, 29, 492-502. [CrossRef]

13. Lupion, M.; Alvarez, I.; Otero, P.; Kuivalainen, R.; Lantto, J.; Hotta, A.; Hack, H. 30 MWth CIUDEN Oxy-CFB boiler-First experiences. In Proceedings of the Energy Procedia; Elsevier Ltd.: Amsterdam, The Netherlands, 2013; T. 37; pp. $6179-6188$.

14. Gogebakan, Z.; Gogebakan, Y.; Selçuk, N. Co-Firing of Olive Residue with Lignite in Bubbling FBC. Combust. Sci. Technol. 2008, 180, 854-868. [CrossRef]

15. Bhuiyan, A.A.; Naser, J. Computational modelling of co-firing of biomass with coal under oxy-fuel condition in a small scale furnace. Fuel 2015, 143, 455-466. [CrossRef]

16. Al-Mansour, F.; Zuwala, J. An evaluation of biomass co-firing in Europe. Biomass Bioenergy 2010, 34, 620-629. [CrossRef]

17. Prawisudha, P.; Triyono, B.; Rorimpandey, K.; Irhamna, A.R.; Hardianto, T.; Pasek, A.D. Development of torre-briquetting process to convert mixed MSW into high energy density solid fuel. In Proceedings of the AIP Conference Proceedings; T. 1984; American Institute of Physics: Melville, NY, USA, 2018.

18. Zhang, L.; Ninomiya, Y.; Wang, Q.; Yamashita, T. Influence of woody biomass (cedar chip) addition on the emissions of PM10 from pulverised coal combustion. Fuel 2011, 90, 77-86. [CrossRef]

19. Bala-Litwiniak, A.; Zajemska, M. Computational and experimental study of pine and sunflower husk pellet combustion and co-combustion with oats in domestic boiler. Renew. Energy 2020, 162, 151-159. [CrossRef]

20. Gendek, A.; Aniszewska, M.; Malat'ák, J.; Velebil, J. Evaluation of selected physical and mechanical properties of briquettes produced from cones of three coniferous tree species. Biomass Bioenergy 2018, 117. [CrossRef]

21. Gill, N.; Dogra, R.; Dogra, B. Influence of Moisture Content, Particle Size, and Binder Ratio on Quality and Economics of Rice Straw Briquettes. Bioenergy Res. 2018, 11. [CrossRef]

22. Lin, T.; Rodríguez, L.F.; Davis, S.; Khanna, M.; Shastri, Y.; Grift, T.; Long, S.; Ting, K.C. Biomass feedstock preprocessing and long-distance transportation logistics. GCB Bioenergy 2016, 8, 160-170. [CrossRef]

23. Mahidin; Saifullah; Erdiwansyah; Hamdani; Hisbullah; Hayati, A.P.; Zhafran, M.; Sidiq, M.A.; Rinaldi, A.; Fitria, B.; et al. Analysis of power from palm oil solid waste for biomass power plants: A case study in Aceh Province. Chemosphere 2020, 253, 126714. [CrossRef]

24. Laimon, M.; Mai, T.; Goh, S.; Yusaf, T. Energy sector development: System dynamics analysis. Appl. Sci. 2020, 10, 134. [CrossRef]

25. Zhao, K.; Jensen, A.D.; Glarborg, P. NO formation during oxy-fuel combustion of coal and biomass chars. In Proceedings of the Energy and Fuels; American Chemical Society: Washington, DC, USA, 2014; T.28; pp. 4684-4693.

26. Jia, L.; Tan, Y.; McCalden, D.; Wu, Y.; He, I.; Symonds, R.; Anthony, E.J. Commissioning of a 0.8MW th CFBC for oxy-fuel combustion. Int. J. Greenh. Gas Control 2012, 7, 240-243. [CrossRef] 
27. Zenkov, A.; Larionov, K.; Yankovsky, S.; Lavrinenko, S. Research of rheological properties improvement methods of coal-water fuel based on low-grade coal. In Proceedings of the MATEC Web of Conferences; American Institute of Physics: Melville, NY, USA, 2017. T.141.

28. Nyashina, G.S.; Vershinina, K.Y.; Shlegel, N.E.; Strizhak, P.A. Effective incineration of fuel-waste slurries from several related industries. Environ. Res. 2019, 176, 108559. [CrossRef] [PubMed]

29. Buravchuk, N.I.; Gur'yanova, O.V. Technology for the Joint Briquetting of Waste Coal and Sawdust. Solid Fuel Chem. 2018, 52. [CrossRef]

30. Kuznetsov, G.V.; Yankovsky, S.A.; Tolokolnikov, A.A.; Zenkov, A.V.; Cherednik, I.V. Conditions and characteristics of mixed fuel granules ignition based on coal and finely dispersed wood. Energy 2020, 194, 116896. [CrossRef]

31. Krzywanski, J.; Czakiert, T.; Blaszczuk, A.; Rajczyk, R.; Muskala, W.; Nowak, W. A generalized model of $\mathrm{SO}_{2}$ emissions from large- and small-scale CFB boilers by artificial neural network approach: Part 1 . The mathematical model of $\mathrm{SO}_{2}$ emissions in air-firing, oxygen-enriched and oxycombustion CFB conditions. Fuel Process. Technol. 2015, 137, 66-74. [CrossRef]

32. Gungor, A. Prediction of $\mathrm{SO}_{2}$ and $\mathrm{NO}_{x}$ emissions for low-grade Turkish lignites in $\mathrm{CFB}$ combustors. Chem. Eng. J. 2009, 146, 388-400. [CrossRef] 